\title{
Fifteen-minute consultation: The angry child
}

\section{Annie Swanepoel}

Potters Bar Clinic, Elysium Healthcare, Potters Bar, Hertfordshire, UK

\section{Correspondence to} Dr Annie Swanepoel, Potters Bar Clinic, Elysium Healthcare; annie.panzer@gmail.com

Received 12 November 2017 Revised 11 February 2018 Accepted 29 April 2018 Published Online First 25 May 2018

\section{Check for updates}

To cite: Swanepoel A. Arch Dis Child Educ Pract Ed 2019:104:11-15.

\begin{abstract}
Children who present with difficult behaviours due to underlying anger are commonly presented to paediatricians for help and advice. This paper gives a basic structure of how to approach the subject, by exploring whether the problems occur at home, school or both, and analysing the behaviour by focusing on antecedents, behaviour and consequences. It is important to find the underlying causes in order to know what to recommend, as this can vary from medication, anger management strategies, school-based interventions, parenting programmes or family therapy.
\end{abstract}

\section{ANGER AS A FEELING AND ANGRY ACTIONS}

First of all, it is important to distinguish between anger as a feeling and angry actions. Anger is an important and normal feeling which informs us that something is not right and potentially harmful to us. It is fine to feel angry-however, it is not acceptable to lash out and hurt people or destroy property. When a child is presented with anger issues, it is often angry behaviours that are meant, rather than angry feelings. However, in order to address the behaviours, it is important to get to the bottom of why the child is feeling angry. It is also important to note that anger can be a defence to avoid painful underlying feelings of fear or sadness.

\section{FINDING REASONS FOR ANGRY BEHAVIOURS BY LOOKING AT WHERE THEY ARE DISPLAYED Anger mainly at school}

If the child mainly has anger outbursts at school, it is important to find out whether this happens in the classroom or playground and to get a few recent examples. For example, children with undiagnosed learning difficulties can get very frustrated when they are unable to do what the others can do and thus get very angry when they are asked once again to read or write or do Maths when they know that it is too hard. ${ }^{1}$ Other children may be fine in class, but really struggle with unstructured playtime. This can be because they have social difficulties, for example autism spectrum disorder, and cannot make friends. Some children are very hyperactive and impulsive, as is the case in attention-deficit hyperactivity disorder (ADHD). These children typically struggle to follow rules and often butt into other children's games, which leads to being rejected and feeling angry as a result. ${ }^{1}$ Also, children who tend to get angry easily can be a source of entertainment for others, who may wind them up for the fun of seeing them totally lose their temper. This is, of course, bullying and should be dealt with firmly by the school (see box 1 for reasons for angry behaviours at school).

\section{Anger mainly at home}

If the angry behaviours tend to be confined to home, but not at school, it is reasonable to consider that the parent-child relationship may need improving. Some parents have unrealistic expectations of their children, for example single mothers with sons who expect their sons to be chatty, helpful and conscientious, when they should be looking for that in a partner rather than in a boy. However, it is also important to remember that some children with neurodevelopmental or temperamental difficulties will pull themselves together while at school, but then collapse and let it all out once they are home. Another common cause of anger only at home is when other family members struggle to manage their anger and emotions often run high, and this is seen as normal and acceptable behaviour (see box 2 for reasons for angry behaviours at home).

If physical altercations occur between adults and children, it is important to get the history of the sequence of events. In these cases, there typically is a history of physical chastisement of the child in the past. The child then learns that if you are 
Box 1 Reasons that children can present with angry behaviours at school

- Being unable to do the work due to specific or general learning difficulties.

- Being unable to make friends—consider autism spectrum disorder.

- Bullying from other children.

- Attention-deficit hyperactivity disorder-being told off constantly by teachers for calling out and fidgeting, while they are subjectively trying to do their best.

- Communication or language difficulties.

- Harsh teaching styles.

- In order to be sent out of class or excluded, if that is preferable to being in class.

really angry, you respond by hitting. This can then lead to either party starting to hit out of anger, and the other party retaliating to defend themselves. In England and Wales it is still lawful for a parent to hit a child as punishment, as long as no implement is used and no mark is left. It is not lawful for a child to hit a parent. This can lead to the distressing situation where a parent hits a child as chastisement and the child hits back in anger. Some parents then call the police, who tell the child off, even though the child is younger and weaker than the parent. In cases of significant emotional and/or physical altercations between parents and children, it is important to make a referral to Children's Services due to safeguarding concerns. Even if the concerns do not reach the threshold for Section 17 (Child-in-Need) or Section 47 (Child Protection), services may still be available to support the family to learn to change their communication styles and to decrease the stress that they are under.

\section{Anger both at home and at school}

Some children present with significant anger and behaviour problems both at home and at school. In these children, it is important to get a longitudinal and

Box 2 Reasons that children can present with angry behaviours at home

- Unrealistic expectations from parents-either expecting too much or infantilising the child.

- Seeing anger and violence modelled by parents.

- Difficult living conditions/low socioeconomic status.

- Parental stress or conflict.

- Boredom.

- Feeling misunderstood or falsely accused.

- Culture clash between what child learns is acceptable at school and what parents expect.

- Authoritarian parenting style with harsh discipline.

- Parent with mental health problems, unable to provide care or boundaries.

- Neurodevelopmental or learning problems that make children more difficult to parent.
Box 3 Reasons that children can present with

angry behaviours both at home and at school

- Any combination of the factors in boxes 1 and 2 .

- Child factors: underlying learning or neurodevelopmental difficulties.

- Significant family problems that cause the child's behaviour to spill over at school, for example unconsciously trying to be excluded in order to be home to care for a parent who may be suicidal.

- Safeguarding concerns in children who are suffering maltreatment.

- History of abuse, resulting in child being hypervigilant to any threat and over-reacting.

- History of neglect, where child acts up to get attention, as even negative attention is better than 'being forgotten'.

- Depression can present as irritability and hopelessness in children, which can lead them to feel that they will never be able to change.

- Some children are temperamentally more difficult and irritable ${ }^{9}$ and need more warmth and skill in raising them than most.

developmental history. Children can, of course, also have two or more problems that are not related, for example dyslexia and a parent with a mental health problem. Children whose behaviours are dangerous to themselves or others and children with significant behavioural difficulties both at home and at school may benefit from a referral to Child and Adolescent Mental Health Services for a full psychosocial assessment and if indicated a screen for neurodevelopmental problems $^{2}$ (see box 3 ).

\section{STRUCTURED APPROACH TO THE ANALYSIS OF ANGRY BEHAVIOUR}

In terms of understanding more about the angry behaviour, it helps to ask about the antecedents, the problem behaviour and the consequences: the $\mathrm{ABC}$ of a behaviour analysis (see box 4). That means asking about what led up to the behaviour, the detail of the behaviour and what the consequences were. If a child finds that angry behaviours get them what they want, these behaviours will be reinforced - the typical example being a child who has a tantrum in a shop as they have learnt that this will push their parents into buying them what they want. ${ }^{3}$ In schools, it is very important to think about the consequences, as some children prefer being excluded as punishment, as they then do not have to face school. Exclusion can then inadvertently become a reward for bad behaviours. In more complex family situations, children can sometimes unconsciously act out at home, in order to defuse a conflictual parental relationship-thus acting as a lightning rod to pull anger from the parents towards each other to rather focus on the 
Box 4 Some questions to ask for a behavioural

\section{analysis}

Antecedents
When did this happen?
How were you feeling? Consider hunger, tiredness
and stress.
What was the trigger?
How much time did you have to think about it? Check for
impulsivity versus calculated behaviour.
What were you thinking/planning?
What did you do?
Behaviour
What happened?
Who was involved?
How did you feel?
What were you thinking?
How did you act?
Consequences
What happened then?
How did you feel about it? Check for remorse/relief.
What did you think then?
What do you think about it now?
What effect did it have on other people?

child. The consequence is then that the parental relationship is stabilised, but at the cost of the child being scapegoated.

\section{TREATMENT}

The treatment of angry behaviours in a child depends on the reason for it. It goes without saying that sometimes it is more effective to work with the adults in the child's life than with the child. ${ }^{4}$ For example, a child with learning difficulties may settle down very nicely once they are given the support they need and the work is pitched at the right level. Also, children tend to take their cues from their parents, and if parental stress is reduced, perhaps through mental health support or financial advice, this can help the child without the child having to be aware of what is being put in place. Parenting programmes ${ }^{5}$ can also be extremely helpful-especially for parents who did not receive warm and sensitive parenting themselves and may fall back on the default harsh parenting they received. Some parents may be unable to set down boundaries at all, as they cannot bear to be strict like their own parents were. Parenting programmes specifically for parenting teenagers can be invaluable, as a new skill set is needed and the techniques that used to work with younger children are not effective with teenagers anymore. Also, it is imperative that all parenting programmes focus on building a more positive relationship with the child, as discipline on its own will not work if the child does not have goodwill towards the parent.

Schools vary greatly in their ability to manage difficult behaviours. Some schools are brilliant and have excellent strategies in place to be proactive to prevent escalations, for example by providing nurture groups and clear rules with a lot of warmth and praise for good behaviour. Offering social skills support and help to make friends, for example in a buddy system, can be highly effective. Unfortunately, there are also schools that get into very adversarial positions with their students and this can lead to unnecessary and damaging escalations in conflict. Most schools have access to advice from expert behaviour support teams and it can be useful to suggest that this resource is used.

Individual anger management strategies for the child will often only be effective if changes are put in place at home and/or school as well. ${ }^{4}$ Children can be taught techniques like counting to 10 before they respond, taking a few deep breaths, walking away and talking to a trusted adult. Cognitive behavioural therapy can also be helpful in some cases. ${ }^{5}$ Of course, if the child meets the diagnostic criteria for ADHD, medication can help decrease impulsivity and give the child time to think before responding.

Children who have suffered developmental trauma, such as abuse and neglect, have learnt to expect that the world is dangerous and that others are out to hurt them. ${ }^{6}$ They may thus be on high alert and misinterpret neutral signals as threats, which then triggers their fightor-flight response. Such children may think that they are defending themselves, while objectively they appear to be the aggressor. These children need a calm, consistent and warm approach, with explanations given to reassure them and to help them relax. Professional help is only indicated once the child is in a safe environment both at home and at school. This is because therapeutic support should not be used to make a dangerous or inappropriate situation bearable, as that would be colluding with the parents and/or school that the problem is located solely in the child when this is not the case.

In the context of anger, it is also important to mention the rare cases of children who have callous-unemotional traits. ${ }^{7}$ These children tend to not respond as much with 'hot' anger outbursts, but tend to be cold and calculated. Often children without callous-unemotional traits will feel remorse after an outburst, whereas children with these traits may be remorseful only because they were caught. The main differential is the lack of impulsivity and degree of forethought in children with callous-unemotional traits. These traits have a poor prognosis and tend to persist, leading to criminal and antisocial behaviours later in life, which may or may not be formally recognised.

Specialist schools for children with emotional and behavioural problems typically have a simple strategy to try to turn around problem behaviours. They try to ignore negative behaviours as far as possible and focus on and reward positive behaviours. One strategy is to give each child a significant sum of money per week but subtracting money for each misdemeanour. The important point is that even children with terrible 
Box 5 Strategies to decrease and manage anger outbursts for both children and adults

Decrease level of anger.

- Avoid hunger by providing regular meals, especially breakfast to prevent school-related outbursts.

- Avoid tiredness through regular bed times to ensure enough sleep.

- Exercise.

\section{Manage anger outburst in self.}

- Count to 10 before responding.

Dalk away.

- Breathe deeply a few times.

- Clench and unclench fists.

- Punch a pillow/mattress.

- Distraction, for example, listening to music and doing something different.

- Positive self-talk: "I can manage, I can keep calm, I will deal with this."

- Talk to a trusted adult or friend.

After an anger outburst, it is important to wait until everyone is calm and to talk it through, trying to find ways to avoid it from happening in future. The child needs to understand that everyone makes mistakes, but that it helps to think these through and learn from them in order to do better next time. This is of course equally true for adults managing the child. It can help to remember that children need love most at times when they least deserve it.

behaviour should still have something left at the end of each week, which will then motivate them to improve their behaviour to get more the next time around. They need to have a taste of success before they will get hooked and try to improve further. Teachers are also trained to 'catch them out doing things right' and to praise them for that. The main principle is that children respond to attention, and as adults we can influence whether they get negative attention for bad behaviour or positive attention for good behaviour, keeping in mind that whatever attention they get is likely to increase the behaviour they got it for. These principles are clearly also applicable to the home situation (see box 5 for general strategies to decrease anger and box 6 for a case vignette).

It is important to help children with anger, as they are at risk of problematic interpersonal relationships and negative outcomes in terms of both physical and mental health if they do not receive support. ${ }^{8}$

\section{CONCLUSION}

Children are angry for many reasons, and it is important to find the reason before deciding on which response is most likely to be of help. Simply recommending the same strategy for each case, whether this be parenting programmes or anger management for the child, will not be helpful in some cases, and it is hoped that the structure provided in this paper will aid in the assessment and signposting of children to help them not feel so angry anymore.

\section{Box 6 An example of an angry child}

\section{Background}

Ryan is 12 years old and presents with angry outbursts both at school and at home. He is on the verge of permanent exclusion at school, and his grandparents are struggling to manage him since Children's Services arranged for them to be his primary carers. Background information includes that Ryan's mother uses drugs and drinks, and that he witnessed domestic violence when he was younger and in her care.

\section{Assessment}

- School: Ryan states that he wants to be able to behave in school, but he keeps being told off by teachers for not sitting still and calling out. He also struggles to keep friends, as other children won't let him join their games as they say he does not stick to the rules.

- Home: Ryan is not sure about wanting to be good at home, because he hopes that he will be able to go back to his mother if his grandparents cannot cope with him. His grandparents struggle to manage him as he won't sit still and is easily bored. His sleep is poor.

- Based on the history at school and at home, Conners Questionnaires are requested and Ryan scores were high on attention-deficit hyperactivity disorder (ADHD) measures.

\section{Treatment and recommendations}

- Ryan is diagnosed with ADHD and treated with atomoxetine and told he needs to eat breakfast every day.

- His social worker explains to him that he will not go back to his mother if the placement with his grandparents breaks down, but will rather be placed in care with a stranger.

- School is informed about ADHD and Ryan's history of trauma and asked to put measures in place to help him feel safer; for example, Ryan said that he prefers sitting at the back of class and to have a time-out card if he cannot cope, so that he can leave and go to the library without having to act up to be sent out.

- Grandparents attend a parenting course to manage teenage behaviour, to try and shift their parenting style towards a warmer and more sensitive approach. Following this they agree to facilitate Ryan's wish to play football regularly. Previously they had refused based on his bad behaviours.

- Ryan is taught to concentrate on his breathing, count to 10 , walk away and talk to a named teacher/counsellor if he feels upset.

\section{Outcome}

Following all of the above, Ryan's behaviour improves dramatically over the next few weeks and months, enabling him to stay at school and with his grandparents. He is now at the point where he is beginning to be able to use school counselling to think about his past and his relationship with his mother.

Funding The authors have not declared a specific grant for this research from any funding agency in the public, commercial or not-for-profit sectors. 
Competing interests None declared.

Provenance and peer review Commissioned; externally peer reviewed.

(c) Article author(s) (or their employer(s) unless otherwise stated in the text of the article) 2019. All rights reserved. No commercial use is permitted unless otherwise expressly granted.

\section{REFERENCES}

1 Potegal M, Carlson GA, Margulies D, et al. The behavioral organization, temporal characteristics, and diagnostic concomitants of rage outbursts in child psychiatric inpatients. Curr Psychiatry Rep 2009;11:127-33.

2 Blake CS, Hamrin V. Current approaches to the assessment and management of anger and aggression in youth: a review. J Child Adolesc Psychiatr Nurs 2007;20:209-21.

3 Daniels E, Mandleco B, Luthy KE. Assessment, management, and prevention of childhood temper tantrums.

J Am Acad Nurse Pract 2012;24:569-73.
4 Jensen PS. The role of psychosocial therapies in managing aggression in children and adolescents. J Clin Psychiatry 2008;69(Suppl 4):37-42.

5 Sukhodolsky DG, Smith SD, McCauley SA, et al. Behavioral Interventions for Anger, Irritability, and Aggression in Children and Adolescents. J Child Adolesc Psychopharmacol 2016;26:58-64.

6 Swanepoel A, Sieff DF, Music G, et al. How evolution can help us understand child development and behaviour. BJPsych $A d v$ 2016;22:36-43.

7 Roth G, Strüber D. [Neurobiological aspects of reactive and proactive violence in antisocial personality disorder and "psychopathy"]. Prax Kinderpsychol Kinderpsychiatr 2009;58:587-609.

8 Kerr MA, Schneider BH. Anger expression in children and adolescents: a review of the empirical literature. Clin Psychol Rev 2008;28:559-77.

9 Leibenluft E. Pediatric irritability: a systems neuroscience approach. Trends Cogn Sci 2017;21:277-89. 